\title{
ESPÉCIES AMEAÇADAS: O ESTUDO DE CASO DO PODER PÚBLICO EM DEFESA DO MEIO AMBIENTE
}

\author{
Gláucio Costa de Menezes ${ }^{1}$ \\ Isabel Lausanne Fontgalland ${ }^{2}$
}

RESUMO: Ao longo do período 198I-202I, a legislação ambiental brasileira foi sendo estruturada e atualizada, de forma que atualmente, é um dos mais completos conjuntos de leis ambientais do mundo. A preservação da fauna, punindo ações criminosas, praticadas por indivíduos que exercem atividades ilegais, está pautada nas Leis no 9.605/1998 e n⿳0 5.197/1969. Sendo assim, o objetivo do estudo em tela foi analisar a atuação da Polícia Militar, na proteção de espécies ameaçadas e seus ecossistemas em perigo no Estado da Paraíba, de maneira a subsidiar a tomada de decisão dos órgãos operativos de preservação e proteção do meio ambiente. Utilizou-se por método de estudo - o estudo de caso, satisfatoriamente adequado para responder as subsequentes indagações à presente pesquisa. Outrossim, o trabalho aqui proposto é revestido de relevância científica e social, podendo servir de base para avanços na proteção ambiental, no combate ao tráfico de animais silvestres e na garantia dos direitos da sociedade a um meio ambiente equilibrado, bem como para outros estudos nas áreas de Direito Ambiental, Segurança Pública e de Gestão de Recursos Naturais.

Palavras - chaves: Polícia. Meio ambiente. Leis. Aves. Tráfico. Animais silvestres.

\section{INTRODUÇÃO}

Participando do esforço mundial, em prol do meio ambiente, em 198I, o Brasil homologou a sua Política Nacional do Meio Ambiente (PNMA), tendo "por objetivo a preservação, melhoria e recuperação da qualidade ambiental propícia à vida, visando assegurar, no País, condições ao desenvolvimento socioeconômico, aos interesses da segurança nacional e à proteção da dignidade da vida humana" (BRASIL, I98I). Neste mesmo instrumento normativo, foi criado o Sistema Nacional do Meio Ambiente (SISNAMA), responsável pela implementação e fiscalização da PNMA.

\footnotetext{
${ }^{\mathrm{I}}$ Mestrando em Gestão de Recurso Naturais pelo Programa de Pós-Graduação em Engenharia e Gestão de Recursos Naturais - PPEGRN da Universidade Federal de Campina Grande - UFCG. Graduado em Ciências Econômicas pela Universidade Federal de Campina Grande (UFCG). Graduado em Segurança Pública pela Academia de Polícia Militar do Cabo Branco (APMCB). Graduado em Ciências Jurídicas pela Universidade Estadual da Paraíba (UEPB). E-mail: glauciocostam@hotmail.com.

${ }^{2}$ Professora titular e orientadora do Programa de Pós-Graduação em Engenharia e Gestão de Recursos Naturais da Universidade Federal de Campina Grande (UFCG). Doutora em Economia Industrial pela Université de Sciences Sociales de Toulouse I da França; pós-doutora em Economia pelo Ohio University of EUA. E-mail: isabelfontgalland@gmail.com.
} 


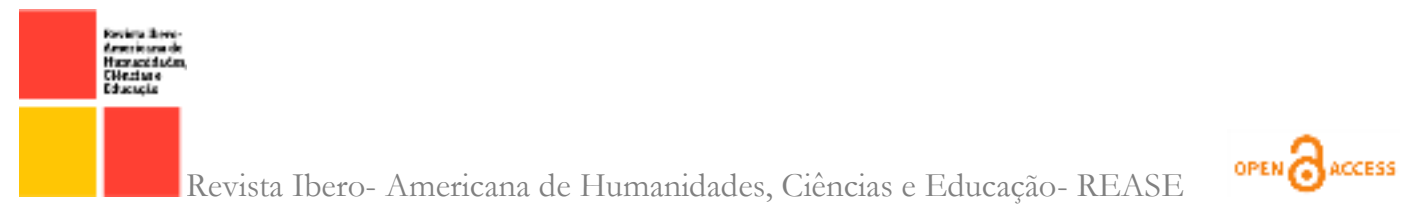

Em 1988, a Constituição Federal brasileira, em seu artigo 225, estabeleceu que "todos têm direito ao meio ambiente ecologicamente equilibrado, bem de uso comum do povo e essencial à sadia qualidade de vida, impondo-se ao Poder Público e à coletividade o dever de defendê-lo e preservá-lo para a presente e futuras gerações" (BRASIL, I988).

Nesse conjunto se destacam a Lei de Crimes Ambientais (BRASIL, 1998) e a Lei no 5.197 (BRASIL, 1969) que tratam de proteger e preservar a nossa fauna e flora. E, sendo o Brasil uma República Federativa, evidentemente as leis federais, que atuam como "norma geral”, influenciaram e modificaram as legislações das unidades federativas do país, dentre as quais a legislação ambiental do Estado da Paraíba.

Para colocar em prática todas as normas jurídicas de proteção e preservação do meio ambiente, além dos órgãos seccionais do SISNAMA (órgãos ou entidades estaduais, responsáveis pela proteção da qualidade ambiental e pelo disciplinamento do uso dos recursos ambientais), é necessária a colaboração de vários órgãos públicos. Entre estes, destaca-se a Polícia Militar da Paraíba, através do Batalhão de Polícia Ambiental, com sede na capital, João Pessoa, e atuação em todos os municípios do Estado - criado pela Lei Complementar no 87, de 02 de dezembro de 2008, que dispõe sobre a organização estrutural e funcional da Polícia Militar e determina outras providências (PARAÍBA, 2008) - e que se constitui importante peça da engrenagem estatal criada com o intuito de evitar a prática de crimes ambientais.

Um dos crimes ambientais que atualmente vem crescendo e se especializando é o tráfico de animais silvestres, notadamente o de aves. A Polícia Militar, no uso e gozo do seu poder de polícia ambiental, e fundamentada no princípio da supremacia do interesse social sobre o individual, com amparo na legislação federal e estadual, tem procurado dissuadir diuturnamente a prática dessa atividade econômica ilegal.

Tendo em vista o exposto, surgem algumas questões: (a) Quais as contribuições da Polícia Militar para a defesa de espécies ameaçadas e dos ecossistemas em que elas estão inseridas no Estado da Paraíba? (b) A atuação do Batalhão de Polícia Ambiental é contribuição adequada e suficiente para evitar a prática dos crimes ambientais, no território paraibano, relacionados ao tráfico de animais silvestres? e (c) Em termos de normas legais e operacionais, como essa atuação poderia ser aprimorada? 


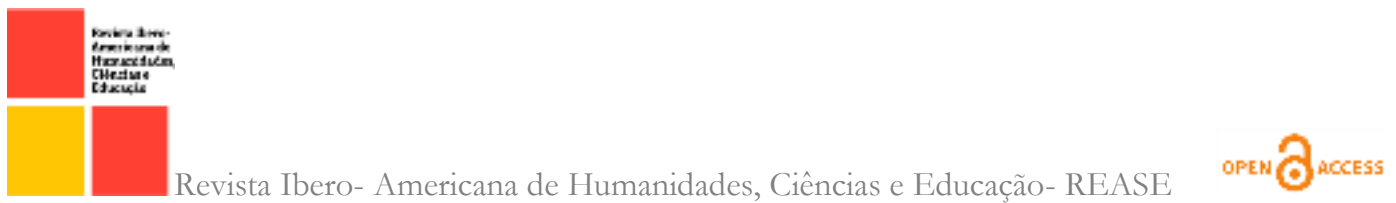

Sendo assim, o presente trabalho, realizando um estudo de caso sobre a atuação da Polícia Militar na defesa de espécies ameaçadas e seus ecossistemas em perigo no Estado da Paraíba, tentará responder as indagações acima expostas, e se caracterizará, quanto aos métodos de investigação, em observacional e indutivo, quanto aos fins, em descritivo e explicativo, e quanto aos meios, em bibliográfico e documental.

\section{O PODER PÚBLICO E O COMBATE AO TRÁFICO DE ANIMAIS SILVESTRES NO ESTADO DA PARAÍBA}

De acordo com o Io Relatório Nacional sobre o Tráfico de Animais Silvestre (200I), o comércio ilegal de vida silvestre, incluindo a fauna, a flora e seus produtos e subprodutos, é extremamente rentável e é considerada a terceira maior atividade ilícita no mundo, atrás apenas do tráfico de armas e do tráfico de drogas.

O comércio de animais silvestres capturados na natureza sempre foi uma atividade deletéria para a fauna, independentemente de ser legal ou ilegal. O processo de comercialização, técnicas de captura, transporte e manejo, de uma maneira geral, são os mesmos desde o início até hoje, com agravantes por atualmente ser uma atividade ilegal. Os animais sempre foram tratados de uma maneira desrespeitosa, vistos apenas como simples mercadorias, utilizados como fonte de renda. (RENCTAS, 20or).

Atualmente, essa atividade ilegal vem crescendo, se especializando e se tornando um dos principais problemas ambientais e econômicos a ser resolvido no Brasil e no mundo. (RENCTAS, 200I).

Dentre as inúmeras ações ambientais realizadas pelos policiais, encontra-se o combate ao tráfico ilegal de animais silvestres, crime este que constitui uma grande ameaça à biodiversidade, sendo um dos fatores mais significativos de destruição da fauna, principalmente em países como o Brasil, que possui altos índices de tráfico de animais (SALDANHA; PEIXOTO, 202I).

No caso da Polícia Militar do Estado da Paraíba, ela vem atuando diuturnamente no combate a esse tipo de crime, objetivando sempre a prisão dos infratores das leis ambientais relacionadas à fauna e o salvamento, ou resgate, de animais ameaçados de algum tipo de violência.

$\mathrm{Na}$ Tabela or abaixo, veremos o quantitativo de animais resgatados pela Polícia Militar em 2020 e o de animais entregues voluntariamente aquela instituição pelo seus suposto criadores. 
Tabela or: Quantitativo de animais resgatados e/ou entregues voluntariamente à Polícia Militar da Paraíba no ano de 2020.

\begin{tabular}{|c|c|c|c|c|c|c|c|c|c|c|c|c|c|c|}
\hline \multicolumn{10}{|c|}{ ANIMAIS RESGATADOS E/OU ENTREGUES VOLUNTARIAMENTE } \\
\hline Subunidade & JAN & FEV & MAR & ABR & MAI & JUN & JUL & AGO & SET & OUT & NOV & DEZ & TOTAL \\
\hline $1^{*}$ CPAmb/JP & 128 & 119 & 127 & 181 & 261 & 197 & 258 & 349 & 269 & 291 & 283 & 172 & $\mathbf{2 6 3 5}$ \\
\hline $\mathbf{2}^{*}$ CPAmb/CG & 31 & 29 & 31 & 58 & 91 & 15 & 49 & 46 & 42 & 64 & 32 & 89 & 577 \\
\hline $\begin{array}{c}3^{*} \text { CPAmb/ } \\
\text { Patos }\end{array}$ & 14 & 12 & 2 & 23 & 58 & 35 & 60 & 56 & 41 & 25 & 4 & 9 & $\mathbf{3 3 9}$ \\
\hline TOTAL & $\mathbf{1 7 3}$ & $\mathbf{1 6 0}$ & $\mathbf{1 6 0}$ & $\mathbf{2 6 2}$ & $\mathbf{4 1 0}$ & $\mathbf{2 4 7}$ & $\mathbf{3 6 7}$ & $\mathbf{4 5 1}$ & $\mathbf{3 5 2}$ & $\mathbf{3 8 0}$ & $\mathbf{3 1 9}$ & $\mathbf{2 7 0}$ & $\mathbf{3 5 5 1}$ \\
\hline
\end{tabular}

Fonte: Adaptado do Relatório de Atividades Anual (2020) do Batalhão Ambiental.

$\mathrm{Na}$ tabela acima, podemos ver que durante o ano de 2020 cerca de 3.551 (três mil quinhentos e cinquenta e um) animais foram resgatados ou entregues voluntariamente à Polícia Militar da Paraíba, sendo o mês de agosto onde mais ocorreram situações dessa natureza, com o registro de 45I (quatrocentos e cinquenta e um) animais entregues e/ou resgatados. Já com relação a localização territorial, a capital João Pessoa foi o local onde mais houveram animais salvados, registrando em 2020 um montante de 2.635 (dois mil seiscentos e trinta e cinco) salvamentos.

Um fato importante que deve ser registrado é que, dentre animais resgatados pela Polícia Militar no ano de 2020, a maioria, ou seja, 44\% (quarenta e quatro por cento), aproximadamente, são aves. Em seguida, com 36\% (trinta e seis por cento), vem o resgate de répteis. Por fim, com $20 \%$ (vinte por cento), teremos os animais mamíferos.

No ano de 2020, outra forma de salvar animais silvestres foi apreendendo eles, como podemos observar na figura abaixo:

Tabela 02: Quantitativo de animais apreendidos pela Polícia Militar no ano de 2020.

\begin{tabular}{|c|c|c|c|c|c|c|c|c|c|c|c|c|c|}
\hline \multicolumn{14}{|c|}{ ANIMAIS APREENDIDOS - 2020} \\
\hline Subunidade & JAN & FEV & MAR & ABR & MAI & JUN & JUL & AGO & SET & OUT & NOV & DEZ & TOTAL \\
\hline $\begin{array}{l}\text { 1" CPAmb/ } \\
\text { Joño Pessoa }\end{array}$ & 37 & 94 & 1658 & 237 & 322 & 149 & 88 & 487 & 105 & 40 & 161 & so & 3.428 \\
\hline $\begin{array}{l}\text { 1"CPAmb/ } \\
\text { SUDEMA }\end{array}$ & 0 & 0 & 0 & 13 & 0 & 18 & 0 & 0 & 342 & 1 & 0 & 0 & 374 \\
\hline $\begin{array}{c}2^{\mathrm{a}} \text { CPAmb/ } \\
\text { Campina Grande }\end{array}$ & 82 & 34 & 72 & 252 & 199 & 103 & 104 & 26 & 44 & 23 & 104 & 128 & 1.171 \\
\hline $3^{\text {a }}$ CPAmb/Patos & 9 & 0 & 20 & 81 & 6 & 44 & 191 & 19 & 30 & 13 & 37 & 20 & 470 \\
\hline TOTAL & 128 & 128 & 1.750 & 583 & 527 & 314 & 383 & 532 & 521 & 77 & 302 & 198 & 5.443 \\
\hline
\end{tabular}

Fonte: Adaptado do Relatório de Atividades Anual (2020) do Batalhão Ambiental.

No ano de 2020, conforme demonstrado na tabela acima, foram apreendidos pela Polícia Militar no Estado da Paraíba 5.443 (cinco mil quatrocentos e quarenta e três) animais, sendo 
destes, 3.428 (três mil quatrocentos e vinte e oito) apenas na capital João Pessoa. No município de Campina Grande, foram apreendidos I.I7I (mil cento e setenta e um) animais.

Foto 02: Registro de ações de combate ao tráfico de aves realizadas pela Polícia Militar no ano de 2020 na capital João Pessoa.

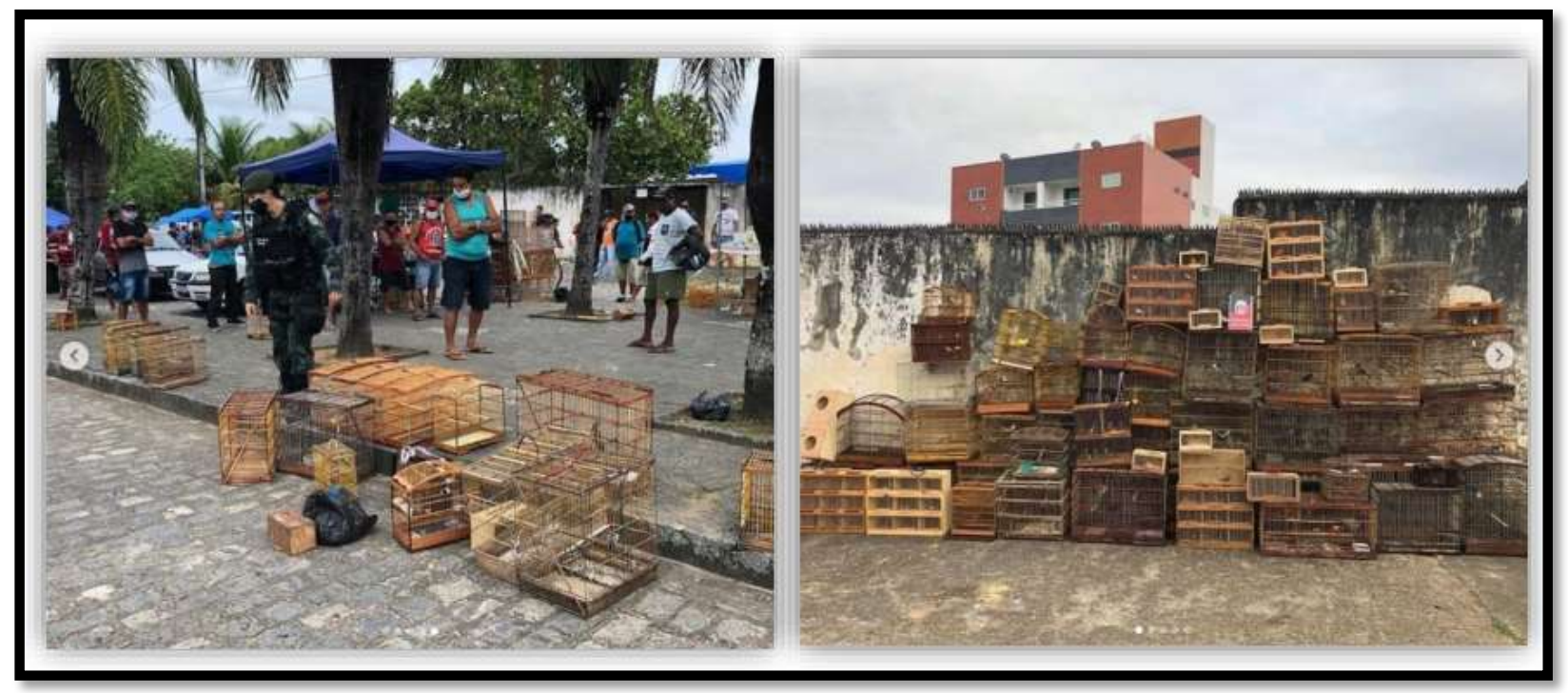

Fonte: Adaptado do Relatório de Atividades Anual (2020) do Batalhão Ambiental.

No município de Campina Grande, área de atuação da 2- Companhia de Policiamento Ambiental ( $2^{-}$CPAmb), conforme tabela abaixo, foram salvados 197 (cento e noventa e sete) animais nas três feiras livres existentes naquele município. A feira da Prata foi a que mais teve ações que resultaram em salvamento de aves em cativeiro, totalizando ro6 (cento e seis) passeriformes.

Tabela 03: Quantitativo de animais salvados pela Polícia Militar em Campina Grande no ano de 2020.

\begin{tabular}{|c|c|c|}
\hline NOME DA FEIRA & MUNICIPIO & $\begin{array}{c}\text { QUNTIDADE DE ANIMAIS } \\
\text { APREENDIDOS }\end{array}$ \\
\hline FEIRA CENTRAL (CG) & $\begin{array}{c}\text { CAMPINA } \\
\text { GRANDE }\end{array}$ & 61 \\
\hline FEIRA DA PRATA & $\begin{array}{c}\text { CAMPINA } \\
\text { GRANDE }\end{array}$ & 106 \\
\hline FEIRA LIVRE & SANTA RITA & 30 \\
\hline \multicolumn{2}{|c|}{ TOTAL } \\
\hline
\end{tabular}

Fonte: Adaptado do Relatório de Atividades Anual (2020) do Batalhão Ambiental.

Embora a cidade de Campina Grande, bem como outras cidades do estado da Paraíba, não esteja incluída entre as cidades com grande participação no tráfico de aves, é comum a venda 
destas em mercados livres, mostrando então a presença de um pequeno tráfico interno. Nas feiras livres, a venda dos pássaros é realizada por 'vendedores ambulantes', que se deslocam com seus pássaros para estes locais nos dias de maior movimento. Um dos principais pontos de comercialização é a Feira da Prata, onde há uma verdadeira feira de passarinhos nos domingos pela manhã. Esta feira é a mais popularmente conhecida, muito embora exista comercialização de aves na feira Central, aos sábados. Esses mercados públicos são amplamente conhecidos, como locais de venda de aves pela população da cidade, até por quem não costuma criar pássaros, o que demonstra o quanto esta atividade está culturalmente disseminada. (ROCHA et al, 2014).

As atividades de venda, revenda e troca de pássaros movimentam um comércio vultoso na cidade de Campina Grande. Além dos pássaros, são comercializadas gaiolas, armadilhas, bebedouros, comida e medicamentos para as aves. Entre as espécies comercializadas, os exemplares machos são mais procurados; as fêmeas só são capturadas para fins reprodutivos ou para estimular o canto dos machos no momento da venda, sendo vendidas por preços mais baixos. (ROCHA et al, 2014).

No ano de 2020, no Estado da Paraíba, a Polícia Militar, através do Batalhão de Policiamento Ambiental, intensificou ações embasada nas legislações acima referendadas no sentido de preservar a fauna paraibana, conseguindo salvar milhares de animais, principalmente aves, dos locais onde se encontravam aprisionados, bem como, aplicando sanções penais e administrativas aqueles que insistem em infringir tais leis, de maneira que ações dessa natureza sejam desestimuladas.

Figura or: Espécies de aves mais resgatadas em 2020 pela Polícia Militar.

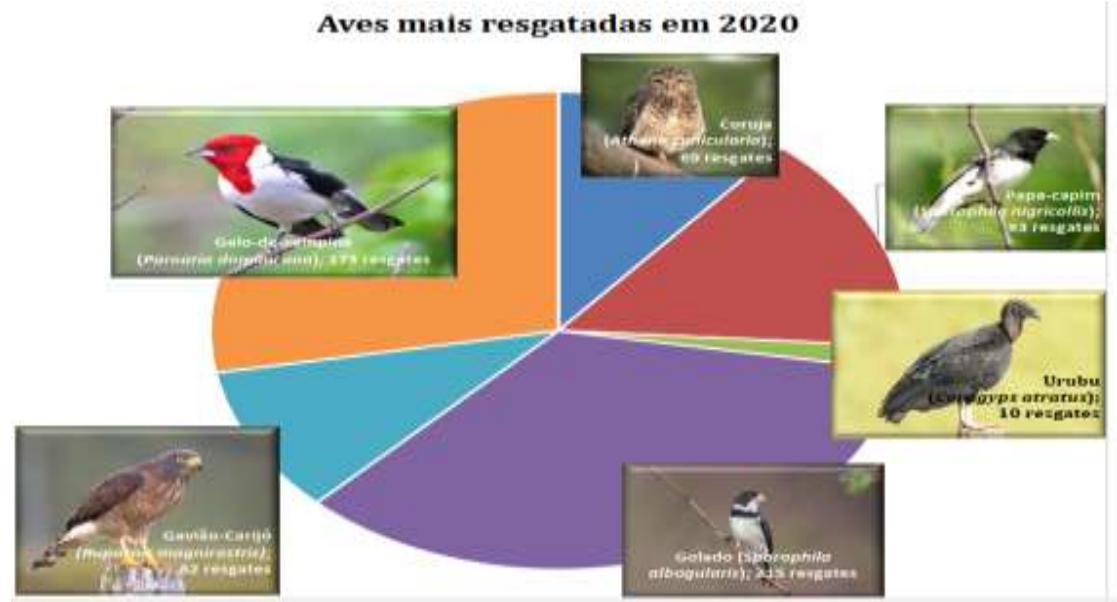

Fonte: Adaptado do Relatório de Atividades Anual (2020) do Batalhão Ambiental. 


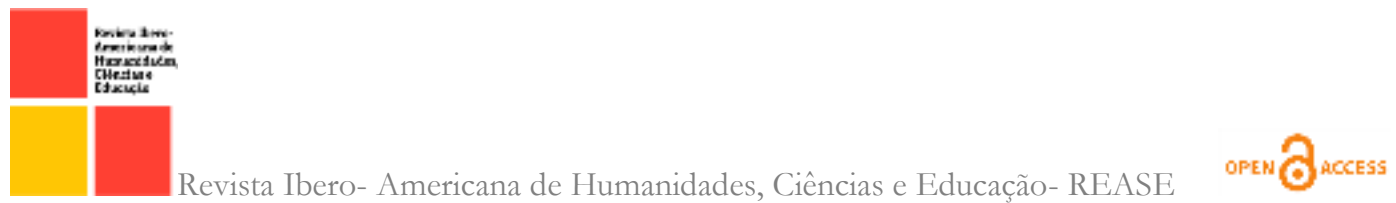

Ao observar as espécies resgatadas pela polícia militar, perceberemos a espécie de ave mais salvada é o chamado golado (sporophila albogularis), com 215 (duzentas e quinze) aves sendo devolvidas para a natureza. Em seguida, vem o Galo-de-Campina, com o resgate em 2020 de 173 (cento e setenta e três) aves. Em Campina Grande, foram resgatados ou entregues voluntariamente, o quantitativo de 498 (quatrocentos e noventa e oito) animais. Essas aves, em sua grande maioria, são conduzidas para o Centro de Triagem de Animais Silvestres (CETAS), localizado na Floresta Nacional da Restinga de Cabedelo, cidade de Cabedelo-PB, o qual é responsável pela recepção, triagem, tratamento e destinação de animais silvestres resgatados ou apreendidos pelos órgãos de fiscalização em diversas localidades da Paraíba, como também dos animais entregues por particulares. (PAGANO et al, 2009).

No ano de 2020, a Polícia Militar realizou 95 (noventa e cinco) prisões de indivíduos que mantinham em cativeiro animais domésticos sem autorização da autoridade competente. Destas, 50 (cinquenta) ocorreram na capital João Pessoa.

No Relatório Anual de Atividades da Polícia Militar, concernente a sua atuação no âmbito da defesa e preservação da natureza, elaborado pelo Batalhão de Polícia Ambiental, em sua versão 2020, consta que foram atendidas pela aquela unidade operacional especializada 334 (trezentas e trinta e quatro) ocorrências relacionadas ao salvamento de animais silvestres que se encontravam em cativeiro de forma irregular. Com relação as multas aplicadas em desfavor dos infratores da lei que mantiveram animais silvestres em cativeiro, em sua grande maioria aves, o montante aproximado de $\mathrm{R}$ I.328.00o,oo (um milhão e trezentos e vinte e oito mil reais), dos mais de $\mathrm{R}_{\$} 4$ milhões aplicadas durante o ano todo resultantes da prática de infrações administrativas ambientais no Estado da Paraíba, o que correspondeu a quase 33\% (trinta e três por cento) do total.

Alguns estudiosos das ciências econômicas dedicaram tempo e esforço no sentido de entender quais os motivos que levariam um homem a não cometer crimes ou contravenções em desfavor da natureza, e principalmente, em detrimento da fauna.

Para COHEN (2000), os economistas que estudam conformidade firme e dissuasão invariavelmente começam com o modelo de "penalidade ideal" de Gary Becker, artigo esse seminal que afirma que os infratores potenciais respondem tanto à probabilidade de detecção, como a severidade da punição se detectado e condenado. Desse modo, continua o brilhante estudioso, a dissuasão pode ser melhorada levantando a caneta alto, aumentando as atividades de 


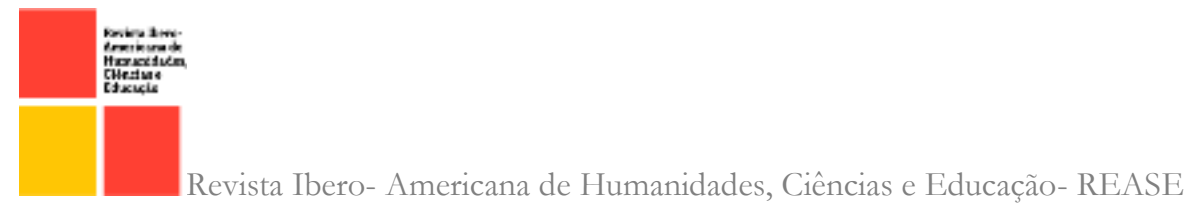

monitoramento para aumentar a probabilidade de que o infrator seja pego, ou mudando a lei e demais regras para aumentar a probabilidade de condenação. O modelo de Gary Becker, em última análise, leva a um nível "eficiente" de crime, em que o custo marginal de execução é igualado ao benefício social marginal da redução do crime. Assim, dado as preferências individuais e as tecnologias de aplicação, tanto a taxa de criminalidade como o nível de monitoramento e fiscalizações das atividades são determinadas por este modelo.

Desse modo, as prisões, apreensões e os valores das multas desencadeadas por ações da Polícia Militar no combate ao tráfico de animais e na manutenção da ordem pública e ambiental, tem como escopo maior a dissuasão da prática de infrações de menor potencial ofensivo contravenções penais - e de crimes contra o meio ambiente praticados.

\section{METODOLOGIA}

A pesquisa em tela trata-se de um estudo de caso, haja vista que o foco principal é a análise da atuação de uma determinada instituição de segurança pública, a Polícia Militar da Paraíba, no combate ao tráfico de aves. De acordo com Brasnski, R. M et al. (20io), a metodologia de estudo de caso divide-se em cinco etapas: delineamento da pesquisa; desenho da

pesquisa; preparação e coleta de dados; análise dos casos de forma individual e comparativa e, finalmente os resultados. Estudos de casos e outras pesquisas qualitativas utilizam, de forma geral, um direcionamento intencional.

Quanto à adequação do estudo de caso, a questão é verificada de acordo com (Yin, 2009) apud Branski (20ı)) et al. que o fenômeno estudado, fornecendo os elementos necessários para verificar as proposições e responder às questões de pesquisa supra.

Para alcançar os objetivos aqui propostos, foram utilizados os métodos observacional e bibliográfico por ser considerado o primeiro passo de um estudo de qualquer natureza e servir de base para qualquer área das Ciências. Dessa forma foi verificado, a partir dos dados coletados junto a Polícia Militar da Paraíba no ano de 2020, que há correlação entre as espécies ameaçadas (aves) e o itinerário do ordenamento jurídico. Quanto aos fins, a pesquisa se caracteriza como descritiva e explicativa, pois expõe características do Batalhão de Policiamento Ambiental, pertencente a Polícia Militar da Paraíba, os dados refletem as informações sobre operações, estatísticas, tabelas do comércio ilegal de aves. Foram também coletadas o quantitativo das ações desempenhadas pelo Batalhão de Policiamento Ambiental no ano de 2020, no combate as formas 
de ameaça dos ecossistemas paraibanos, especialmente com relação ao tráfico de aves e ao salvamento delas de cativeiros irregulares, estabelecendo correlações entre variáveis e definindo sua natureza, de modo a esclarecer o relacionamento entre normas legais e atuação operativa.

\section{CONSIDERAÇÕES FINAIS}

O tráfico de animais silvestres, particularmente de aves, é uma das atividades criminosas mais rentáveis. Segundo o Io Relatório Nacional sobre o Tráfico de Animais Silvestres (200I), esse tipo de crime fica atrás apenas dos tráficos de armas e drogas. As aves são os animais mais encontrados no comércio ilegal, pelo fato de serem os preferidos pelos comerciantes e pela riqueza da avifauna. Mundialmente, o comércio de aves é uma indústria muito variada, movimentando a cada ano cerca de 44 milhões de dólares.

Em 2020, cerca de 3.55I (três mil quinhentos e cinquenta e um) animais foram resgatados ou entregues voluntariamente à Polícia Militar da Paraíba, sendo o mês de agosto, aquele que mais ocorreu situações dessa natureza, com o registro de 45I (quatrocentos e cinquenta e um) animais entregues e/ou resgatados. Já com relação a localização territorial, a capital João Pessoa foi o local onde mais houve animais salvados, registrando em $2020 \mathrm{um}$ montante de 2.635 (dois

mil seiscentos e trinta e cinco) salvamentos. A maioria dos animais resgatados pela Polícia Militar, ou seja, 44\% (quarenta e quatro por cento), aproximadamente, são aves. Em seguida, com $36 \%$ (trinta e seis por cento), vem o resgate de répteis

Com relação aos animais apreendidos, a Polícia Militar realizou 95 (noventa e cinco) prisões de indivíduos que mantinham em cativeiro animais domésticos sem autorização da autoridade competente e foram atendidas 334 (trezentas e trinta e quatro) ocorrências relacionadas ao salvamento de animais silvestres que se encontravam em cativeiro de forma irregular, que resultaram no salvamento de 5.443 (cinco mil quatrocentos e quarenta e três) animais. Em termos de multas, foi aplicado o montante de $\mathrm{R} \$$ 1.328.0oo,oo (um milhão e trezentos e vinte e oito mil reais).

Desse modo, com base nos dados acima, trazidos à baila e quantitativamente e qualitativamente analisados, podemos inferir que houve uma contribuição por demais importante da Polícia Militar da Paraíba no combate ao tráfico de animas silvestres, principalmente com relação as aves, que são os preferidos dos traficantes, comerciantes ilegais 
de animais silvestres e consumidores deste tipo de mercadoria. Ou seja, a atuação do Batalhão ${ }^{3}$ de Polícia Ambiental foi uma contribuição adequada e suficiente para evitar a prática dos crimes ambientais, no território paraibano relacionados ao tráfico de animais silvestres.

Com o intuito de melhorar esta atuação desta unidade especializada em policiamento ambiental, sugestiona-se aos poderes públicos a revisão das leis relacionadas ao crime de tráfico de animais silvestres, com o agravamento das penalidade a ele atribuídas, e aos órgãos responsáveis pela defesa e preservação da natureza, a elaboração de planos de ações conjuntas para o combate deste tipo de ilícito penal ambiental, exercendo cada um à sua função legalmente constituída, o que certamente contribuirá para uma maior otimização e um melhor aproveitamento do potencial de cada órgão participante da ação no que diz respeita a dissuasão dos indivíduos em praticar tais delitos, ganhando ao final a sociedade e o meio ambiente.

Por derradeiro, espera-se que este trabalho incentive outros do gênero, tendo em vista que temas para pesquisa relacionados às espécies ameaçadas são por deverás importantes e o seu conteúdo bastante vasto deve ser mais bem explorado pela comunidade científica, sendo desse modo, impossível esgotá-lo por completo.

\section{AGRADECIMENTOS}

À professora Dra. Isabel Lausanne Fontgalland pela excelente condução da disciplina de Economia e Meio do PPGERN e deste artigo. Ao PPGERN/UFCG.

\section{REFERÊNCIAS}

BRANSKI, R. M.; AURELLANO, R. C. F.; LIMA JUNIOR, O. F. Metodologia de estudo de caso aplicada à logística. In: CONGRESSO DE PESQUISA E ENSINO EM TRANSPORTES (XXIII ANPET), 24., 2010, Salvador. Anais [...], Salvador, 2010.

BRASIL. Constituição da República Federativa do Brasil de 1988. Presidência da República. Disponível em: < http://www.planalto.gov.br/ccivil_03/constituicao/constituicao.htm>. Acesso em: 13 out. 2021.

\footnotetext{
${ }^{3} \mathrm{~A}$ atuação dessa força pública estadual de segurança tem como alicerces o exercício do poder de polícia ambiental, atribuído a ela pela legislação vigente estadual que trata da criação e das atribuições do Batalhão de Polícia ambiental, e o princípio que rege a atividade de polícia administrativa ambiental, que é a supremacia do interesse social sobre o individual, já que o meio ambiente ecologicamente equilibrado ocupa posição de relevo na Constituição da República Federativa do Brasil, sendo um direito fundamental, previsto no artigo 225.
} 


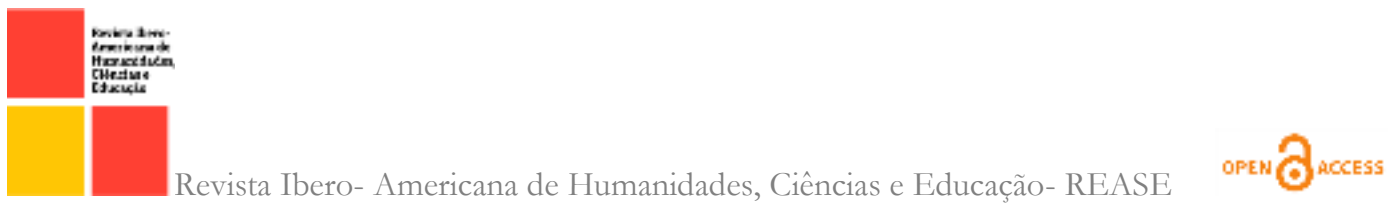

. Lei 5.172, de 25 de outubro de 1966. Dispõe sobre o Sistema Tributário Nacional e institui normas gerais de direito tributário aplicáveis à União, Estados e Municípios. Presidência da República. Disponível em: 〈http://www.planalto.gov.br/ccivil_03/leis/15172compilado.htm〉. Acesso em: 12 out. 2021.

. Lei 5.197, de 3 de janeiro de 1967. Dispõe sobre a proteção à fauna e dá outras providências. Presidência da República. Disponível em:〈http://www.planalto.gov.br /leis/L5197.htm〉. Acesso em: 13 out. 2021.

. Lei 9.605, de 12 de fevereiro de 1998. Dispõe sobre as sanções penais e administrativas derivadas de condutas e atividades lesivas ao meio ambiente, e dá outras providências. Presidência da República. Disponível em: 〈http://www.planalto.gov.br/ccivil_03/leis/l9605.htm >. Acesso em: 13 out. 2021.

CARDOSO, Jorge António de Jesus Soares da Cunha dos Santos. O ambiente, a polícia do ambiente e a investigação criminal do ambiente.

CAVALCANTI, Themistocles Brandão. Tratado de direito administrativo. 5. ed., Vol. III, Rio de Janeiro: Livraria Freitas Bastos S. A., 1964.

CMMAD - Comissão Mundial sobre meio Ambiente e Desenvolvimento. Nosso Futuro Comum. 2ª ed. Rio de Janeiro: Editora da Fundação Getúlio Vargas, 1992. 300 p.

COHEN, Mark A. Empirical Research on the deterrent effect of environmental monitoring and enforcement. Environmental Law Institute, 2000, p. 10245-10.252, Washington, DC.

GHIGNONE, Luciano Taques. Manual ambiental penal: comentários à lei 9.605/98. Decisões judiciais, roteiros práticos, modelos de peças. Ministério Público do Estado da Bahia, Núcleo Mata Atlântica, 2007. 279 p, Salvador. Disponível em: 〈http://www.mp.ba.gov.br/numa〉. Acessado em: 17 out. 2021.

MEDAUAR, Odete. Direito administrativo moderno. $4^{\mathrm{a}}$. ed. São Paulo: Revista dos Tribunais, 2000.

MOREIRA NETO, Diogo de Figueiredo. Curso de direito administrativo, I4. ed. Rio de Janeiro: Editora Forense, 2005

PAGANO, Isales Santos de Alexandria; SOUSA, Antônio Emanuel Barreto Alves de; WAGNER, Paulo Guilherme Carniel; RAMOS, Robson Tamar da Costa. Aves depositadas no Centro de Triagem de Animais Silvestres do IBAMA na Paraíba: uma amostra do tráfico de aves silvestres no estado. Revista Brasileira de Ornitologia 3 (2), p. 132-144, dezembro de 2009, Pernambuco. Disponível em: 〈http://ornithologia.cemave.gov.br/index.php /article/view/45〉. Acesso em: is set. 2021.

PARAÍBA. Lei Complementar nº 87, de 2 de dezembro de 2008. Dispõe sobre a organização estrutural e funcional da Polícia Militar do Estado da Paraíba. Diário Oficial do Estado da Paraíba (03/12/2008). Disponível em: http://www.pm.pb.gov.br /legislacao/Leis_Complementares/2008_DISPOE_SOBRE_A_ORGANIZACAO_ESTRUTU 
RAL_E_FUNCIONAL_DA_POLICIA_MILITAR_DO_ESTADO_DA_PARAIBA_E_DA_OU TRAS_PROVIDENCIAS_.pdf >. Acesso em: I4 set. 202I.

PEREIRA, Glauco Alves; BRITO, Manoel Toscano. Diversidade de Aves Silvestres Comercializadas nas Feiras Livres da Região Metropolitana de Recife, Pernambuco. Atualidades Ornitológicas, n. 126, 2005. p. 14. Disponível em: 〈http://www.ao.com.br/download/glauco.pdf $\rangle$. Acessado em: 9 out. 2021.

POLÍCIA MILITAR DO ESTADO DA PARAÍBA (PMPB). Resolução no oo3 do Comandante Geral de 20 de outubro de 2009. Boletim interno no or8r. Estabelece a divisão geoadministrativa, atribuições e área de responsabilidade territorial dos Comandos Regionais, dos Batalhões, Companhias e Pelotões de Polícia Militar do Estado da Paraíba e dá outras providências. (2009).Disponível em:〈https://www.pm.pb.gov.br/arquivos/portarias/Resolucaoooo3-2009-GCG-Estabelece-a-divisao-geoadministrativa-da-pmpb.pdf >. Acesso em: I3 set. 202I.

. Relatório Anual de Atividades (2020). Batalhão de Polícia Ambiental Lauro Pires Xavier, $\mathrm{P} / 3$ - Seção De Planejamento e Operações.

RENCTAS. 200I. Io Relatório nacional sobre o tráfico de fauna silvestre. Rede Nacional de Combate ao Tráfico de Animais Silvestres, Brasília, ro8p.

ROCHA, Michelle da Silva Pimentel; CAVALCANTI, Priscila Cordeiro de Miranda; SOUSA, Romero de Lima; ALVES, Rômulo Romeu da Nóbrega. Aspectos da comercialização ilegal de aves nas feiras livres de Campina Grande, Paraíba, Brasil. Revista de Biologia e Ciências da Terra, vol. 6, núm. 2, 2006, p. 204-222, Universidade Estadual da Paraíba, Paraíba, Brasil.

RODRIGUES, Miguel Santa Cruz. Tráfico de espécies protegidas - aplicabilidade dos meios

Cinotécnicos no seu combate. 2012. Trabalho de Investigação Individual da Pós-Graduação do CPOS-GNR 2011/2012. Instituto de Estudos Superiores Militares Universidade Nova de Lisboa - Faculdade de Direito, Lisboa, 22 de Agosto de 2012

SALDANHA, Polliana de Oliveira; PEIXOTO, Rosana da Silva. Análise bibliográfica do tráfico de animais silvestres no Nordeste do Brasil na última década. Revista Multidisciplinar do Núcleo de Pesquisa e Extensão (RevNUPE), v. I, n. I, e202102, 2021, p. I - 23, Bahia, Brasil.

SCHMIDT, Cíntia. Poder de polícia ambiental. Revista da ESDM, v. 3, n. 6, Porto Alegre -RS: Brasil, 2017. 